\title{
Consumo, digestibilidade e desempenho de novilhas leiteiras alimentadas com dietas contendo torta de dendê ${ }^{1}$
}

\section{Raylon Pereira Maciel ${ }^{2}$, José Neuman Miranda $\mathrm{Neiva}^{3}$, Vera Lúcia de Araujo ${ }^{4}$, Odislei Fagner Ribeiro Cunha ${ }^{2}$, Joseilson Paiva ${ }^{4}$, João Restle ${ }^{3}$, Clayton Quirino Mendes ${ }^{5}$, Raimundo Nonato Braga Lôbo 6}

\author{
1 Projeto financiado pelo CNPq. \\ 2 Doutorando em Ciência Animal Tropical da Universidade Federal do Tocantins. \\ 3 Universidade Federal do Tocantins. Bolsista do CNPq. \\ 4 Universidade Federal do Tocantins. \\ ${ }^{5}$ Universidade de Brasília. \\ ${ }^{6}$ Embrapa-Caprinos.
}

RESUMO - Objetivou-se avaliar os efeitos da inclusão de torta de dendê na dieta sobre o consumo, a digestibilidade das dietas e o desempenho de novilhas leiteiras. Utilizaram-se 16 novilhas leiteiras mestiças Holandês $\times$ Zebu, com média de 13 meses de idade e peso vivo inicial de 183,4 $\pm 32,5 \mathrm{~kg}$, distribuídas em delineamento inteiramente casualizado, com quatro níveis de torta de dendê $(0 ; 11,9 ; 22,9$ e 34,2\% da matéria seca total), cada um com quatro repetições. Avaliaram-se os consumos de matéria seca (MS), proteína bruta (PB), fibra em detergente neutro (FDN), carboidratos não-fibrosos (CNF), extrato etéreo (EE) e nutrientes digestíveis totais (NDT) e as digestibilidades aparentes da MS, PB, FDN, CNF e EE. Houve redução linear no consumo de MS, PB, FDN, CNF e NDT. A digestibilidade aparente da MS e FDN reduziu com a inclusão da torta de dendê na dieta, enquanto a de PB e dos CNF sofreu efeito quadrático. A inclusão de torta de dendê nas dietas promoveu aumento linear da digestibilidade aparente do extrato etéreo. O ganho de peso reduziu linearmente com a inclusão de torta de dendê na dieta, sendo observados valores de 1,06; 0,99; 0,89 e 0,54 kg/dia para as dietas contendo 0; 11,9; 22,9 ou 34,2\% de torta de dendê na dieta total, respectivamente. A conversão alimentar não foi afetada pelos níveis de inclusão de torta de dendê na dieta. A inclusão de torta de dendê na dieta reduz o consumo de nutrientes e o desempenho de novilhas leiteiras em crescimento, porém, quando utilizada em níveis de até $24,6 \%$ da dieta total, proporciona ganho de peso compatível com os obtidos em programas de recria visando à parição aos 24 meses de idade.

Palavras-chave: biodiesel, Elaeis guineensis, ganho de peso vivo, subproduto, subprodutos do biodiesel, valor nutritivo

\section{Intake, nutrient digestibility and performance of dairy heifers fed diets containing palm kernel cake}

\begin{abstract}
The objective was to evaluate the effects of inclusion of palm kernel cake in the diet on intake, digestibility and performance of dairy heifers. Sixteen dairy Holstein-Zebu crossbred heifers with average age of 13 months and average weight of $183.4 \pm 32.5 \mathrm{~kg}$ were distributed to four treatments in a completely randomized design with four levels of palm kernel cake $(0,11.9,22.9$ and 34.2\% from total dry matter), each one with four replicates. The intake of dry matter (DM), crude protein (CP), neutral detergent fiber (NDF), non-fibrous carbohydrates (NFC), ether extract (EE) and total digestible nutrients (TDN), and the apparent digestibility of DM, CP, NDF, NFC and EE were evaluated. There was linear reduction in DM, CP, NDF, NFC, and TDN intake. The apparent digestibility of DM and NDF reduced with the inclusion of palm kernel cake in the diet, while the apparent digestibility of CP and NFC showed quadratic effect. The inclusion of palm kernel cake in the diets resulted in linear increase in the apparent digestibility of ether extract. Weight gain decreased linearly with the inclusion of palm kernel cake in the diet, with values of 1.06, 0.99, 0.89 and $0.54 \mathrm{~kg} / \mathrm{day}$ for diets containing 0, 11.9, 22, 9 or 34.2\% palm kernel cake, respectively. Feed conversion was not affected by the inclusion of levels of palm kernel cake. The inclusion of palm kernel cake in the diet reduces nutrient intake and performance of dairy heifers during growth, but when used in levels up to $24.6 \%$ of the total diet, it provides weight gain compatible with growth programs aiming calving at 24 months of age.
\end{abstract}

Key Words: biodiesel, byproduct, byproducts of biodiesel, Elaeis guineensis, nutritive value, weight gain

Recebido em 17/9/2010 e aprovado em 6/7/2011.

Correspondências devem ser enviadas para: araguaia2007@gmail.com 


\section{Introdução}

A causa mais comum da elevada idade ao primeiro parto em sistemas de produção de gado de leite é a nutrição inadequada das novilhas. O plano nutricional adotado nesses sistemas geralmente não permite que as novilhas atinjam peso adequado à puberdade e concepção precoce, provocando efeitos negativos em sua vida produtiva. Como consequência, a elevada idade ao primeiro parto resulta em aumento no custo de criação de fêmeas leiteiras, o que tem sido apontado como a segunda maior fonte de despesas no sistema de produção de leite (Mendes Neto et al., 2007). Com o intuito de reduzir a idade ao primeiro parto e garantir maior vida produtiva às novilhas, o atendimento das exigências nutricionais dessa categoria é de fundamental importância, pois, de acordo com Sartori (2007), a alimentação deficiente determina atraso na vida reprodutiva e produtiva da matriz. Dessa forma, a antecipação da idade ao primeiro parto é um aspecto importante a ser trabalhado pelos pecuaristas, que, porém, devem se atentar para a viabilidade econômica dessa prática.

A utilização de subprodutos agroindustriais é uma alternativa para viabilizar um plano nutricional que melhore os índices produtivos das novilhas e contribua para a redução dos custos com alimentação. De acordo com Grasser et al. (1995), a inclusão de subprodutos na alimentação de bovinos leiteiros é economicamente justificável, devido ao preço competitivo desses alimentos em relação a alimentos concentrados convencionalmente usados na formulação de rações. Diversos autores (Garcia et al., 2006; Mendes Neto et al., 2007; Castro et al., 2008; Rocha Neto, 2008) avaliaram o desempenho e a viabilidade econômica do uso de subprodutos agroindustriais na dieta de novilhas leiteiras e concluíram que essa é uma alternativa interessante para o produtor reduzir a idade ao primeiro parto com menor custo de alimentação.

Na Região Norte do País, a torta de dendê, subproduto proveniente da produção do biodiesel, tem sido utilizada na alimentação de bovinos, devido à sua disponibilidade e ao baixo custo. Entretanto, poucas são as informações sobre suas características como alimento e seu efeito sobre o desempenho animal, sendo necessárias pesquisas que possibilitem sua caracterização e a definição da melhor forma de utilização em rações para ruminantes.

Com este estudo objetivou-se avaliar os efeitos da inclusão de torta de dendê sobre o consumo e a digestibilidade aparente das dietas e o desempenho de novilhas leiteiras.

\section{Material e Métodos}

Foram avaliadas quatro dietas experimentais contendo $0 ; 12 ; 23$ ou 34\% de torta de dendê na matéria seca total para níveis previstos inicialmente de 0; 12; 24 e 36\%. Utilizaram-se 16 novilhas leiteiras mestiças Holandês $\times$ Zebu com idade média de 13 meses e peso vivo médio inicial de $183,4 \pm 32,5 \mathrm{~kg}$.

Os animais foram identificados com brincos e, previamente ao experimento, receberam medicamento contra ecto e endoparasitas e complexo vitamínico ADE. As novilhas foram alojadas em baias individuais de $12 \mathrm{~m}^{2}$, com piso de chão batido, cobertas, providas de comedouro e bebedouro. O experimento constou de 84 dias, sendo 14 dias para adaptação dos animais e cinco períodos experimentais de 14 dias, perfazendo 70 dias de coleta de dados.

As novilhas foram pesadas no início do experimento, após o período de adaptação, periodicamente a cada 14 dias e ao final dos 84 dias para determinação do ganho de peso. As pesagens foram realizadas sempre pela manhã, antes do fornecimento da dieta.

Após a determinação da composição dos ingredientes (Tabela 1), as dietas experimentais (Tabela 2) foram formuladas de acordo com o NRC (2001). A torta de dendê utilizada neste experimento foi obtida por prensagem mecânica da amêndoa do dendê, para obtenção do óleo usado na produção de biodiesel pela Agroindústria Palmasa S/A.

As dietas foram fornecidas duas vezes ao dia, às $9 \mathrm{~h}$ e às $17 \mathrm{~h}$, em quantidade ajustada para manter sobras de 5 a $10 \%$ do fornecido. A quantidade de ração fornecida e de sobras de cada animal foi registrada diariamente para estimativa do consumo de matéria seca e dos nutrientes. Semanalmente, foram amostrados a cana-de-açúcar, os concentrados e as sobras. As amostras foram acondicionadas em sacos plásticos, congeladas e posteriormente compostas em períodos de 14 dias. Todas as amostras foram pré-secas em estufa ventilada a $55^{\circ} \mathrm{C}$ por 72 horas, moídas em moinho com peneira de crivos de $1 \mathrm{~mm}$ e armazenadas para posteriores análises laboratoriais.

As análises bromatológicas dos alimentos, das sobras e das fezes foram realizadas no Laboratório de Nutrição Animal da Escola de Medicina Veterinária e Zootecnia da Universidade Federal do Tocantins. As determinações de matéria seca, matéria orgânica, proteína bruta, nitrogênio insolúvel em detergente neutro, nitrogênio insolúvel em detergente ácido, extrato etéreo, lignina, cinzas, cálcio e fósforo foram realizadas conforme metodologias descritas por Silva \& Queiroz (2002). Os teores de fibra em detergente 
neutro e fibra em detergente ácido foram determinados conforme descrito por Van Soest et al. (1991).

Os valores dos carboidratos não-fibrosos foram obtidos por meio da equação: $\mathrm{CNF}=100-[(\% \mathrm{~PB}-\%$ PB da ureia + \% ureia) + FDNcp + \%EE + \%Cinzas], proposta por Hall (2000), e os carboidratos totais foram determinados por meio da equação: 100 - (\% PB + \% EE + \%Cinzas), de acordo com Sniffen et al. (1992).

O teor dos nutrientes digestíveis totais (NDT) da canade-açúcar, torta de dendê e das dietas foram calculados

Tabela 1 - Composição química dos ingredientes (g/kg) utilizados na formulação das dietas experimentais

\begin{tabular}{|c|c|c|c|c|}
\hline \multirow[t]{2}{*}{ Item } & \multicolumn{4}{|c|}{ Ingrediente } \\
\hline & Milho & Farelo de soja & Torta de dendê & Cana-de-açúcar \\
\hline Matéria seca & 887,7 & 872,3 & 925,4 & 249,3 \\
\hline Matéria orgânica & 976,0 & 928,5 & 962,5 & 972,3 \\
\hline Proteína bruta & 90,6 & 458,5 & 154,6 & 22,1 \\
\hline Fibra em detergente neutro & 149,4 & 153,9 & 716,7 & 548,7 \\
\hline Fibra em detergente ácido & 58,2 & 99,8 & 441,4 & 335,1 \\
\hline Hemicelulose & 91,2 & 54,1 & 275,3 & 213,6 \\
\hline Carboidratos não-fibrosos & 744,7 & 300,0 & 125,0 & 407,1 \\
\hline Carboidratos totais & 851,6 & 459,2 & 699,3 & 936,6 \\
\hline Nutrientes digestíveis totais ${ }^{1}$ & 872,4 & 815,4 & 604,5 & 638,4 \\
\hline Celulose & 47,3 & 87,4 & 289,8 & 268,2 \\
\hline Lignina & 10,2 & 10,9 & 162,3 & 55,3 \\
\hline Cinzas & 15,5 & 63,2 & 37,5 & 27,7 \\
\hline Nitrogênio insolúvel em detergente neutro ${ }^{2}$ & $8,63(9,53)$ & $22,37(4,88)$ & $123,92(80,16)$ & $7,74(35,03)$ \\
\hline Nitrogênio insolúvel em detergente ácido² & $3,47 \quad(3,84)$ & $12,61(2,75)$ & $57,57(37,24)$ & $2,33(10,58)$ \\
\hline Extrato etéreo & 42,3 & 19,1 & 108,6 & 13,6 \\
\hline Cálcio & 0,6 & 2,3 & 3,4 & 2,0 \\
\hline Fósforo & 3,2 & 5,8 & 5,6 & 0,6 \\
\hline
\end{tabular}

${ }^{1}$ NDT estimado pelas equações do NRC (2001).

2 Os valores entre parênteses correspondem ao valor expresso em \% do nitrogênio total.

Tabela 2 - Proporção dos ingredientes e composição química das dietas experimentais

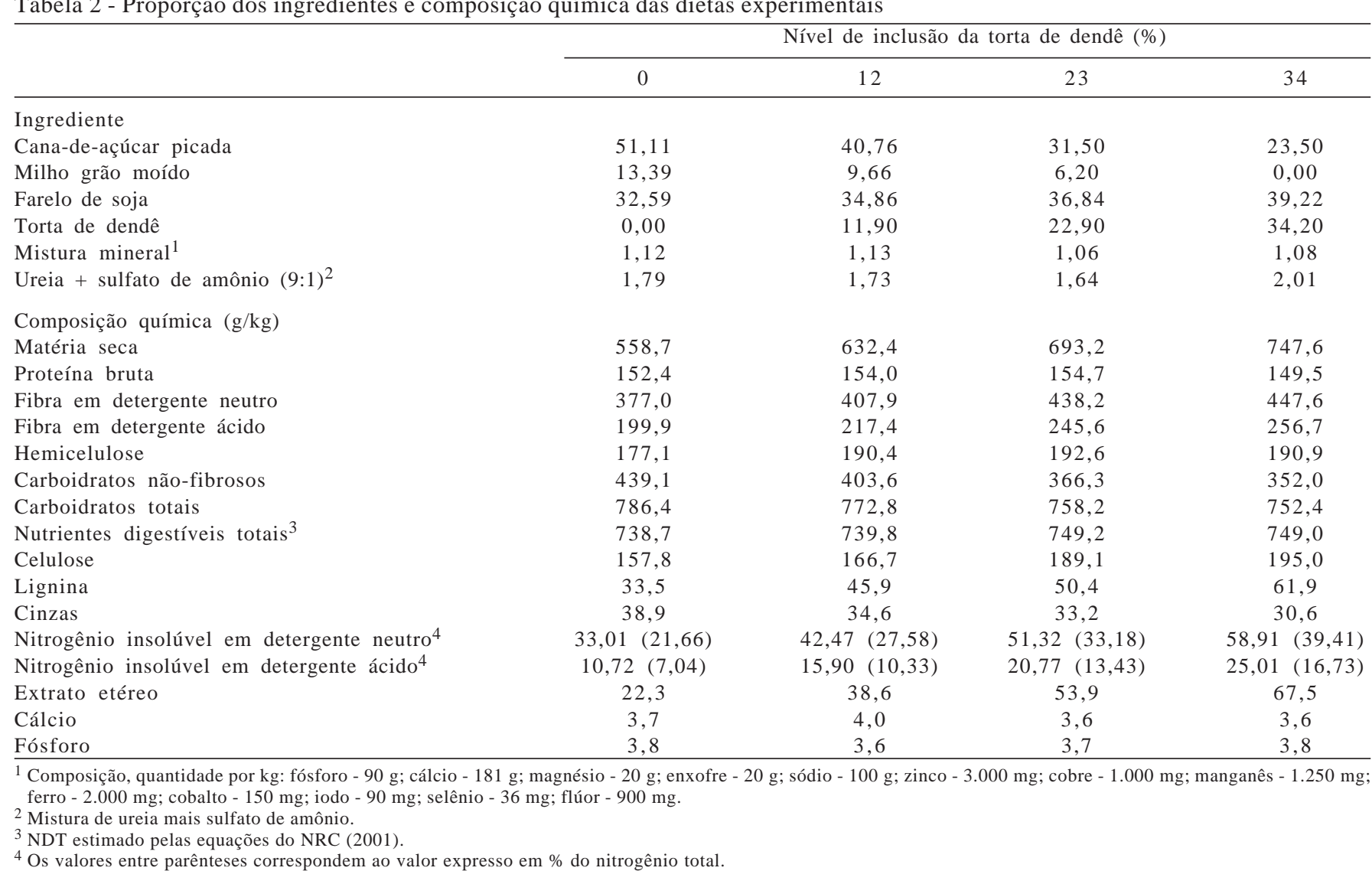


segundo a equação de predição utilizada pelo NRC (2001): $\mathrm{NDT}=\left\{\mathrm{CNF}_{\mathrm{vd}}+\mathrm{PB}_{\mathrm{vd}}+\left(2,25 \times \mathrm{AG}_{\mathrm{vd}}\right)+\mathrm{FDN}_{\mathrm{vd}}\right\}-7$, sendo: $\mathrm{CNF}_{\text {verdadeiramente digestível }}=0,98 \times \mathrm{CNF} \times \mathrm{PAF}$; $\mathrm{PB}_{\text {verdadeiramente digestível }}$ (para forragens) $=\mathrm{PB} \times \exp \{-1,2$ $\times$ (PIDA / PC) $\}$; PB $_{\text {verdadeiramente digestível (para }}$ concentrados $)=\{1-(0,4 \times(\mathrm{PIDA} / \mathrm{PB}))\} \times \mathrm{PB}$; $\mathrm{AG}_{\text {verdadeiramente digestível }}=(\mathrm{EE}-1)$, se $\mathrm{EE}<1$, então $\mathrm{AG}=$ $0 ; \mathrm{FDN}_{\text {verdadeiramente digestível }}=0,75 \times\left(\mathrm{FDN}_{\mathrm{n}}-\mathrm{L}\right) \times\{1-$ $\left.(\mathrm{L} / \mathrm{FDN})^{0,667}\right\}$, em que PIDA = nitrogênio insolúvel em detergente ácido $\times$ 6,25; AG = ácidos graxos, $\mathrm{L}=$ lignina, $\mathrm{e}$ FDNn $=$ FDN - PIDN, PIDN = nitrogênio insolúvel em detergente neutro $\times 6,25$, PAF $=$ fator de ajuste para processamento, sendo utilizado o fator 1 para a torta de dendê e para a cana-de-açúcar.

Os valores de nutrientes digestíveis totais observados foram estimados para as diferentes dietas pela equação: $\mathrm{NDT}=\mathrm{PB}_{\text {digestível }}+\left(\mathrm{EE}_{\text {digestível }} \times 2,25\right)+\mathrm{FDN}_{\text {digestível }}+$ $\mathrm{CNF}_{\text {digestível }}$ (Sniffen et al., 1992).

A avaliação da digestibilidade foi realizada no final do último período experimental, quando amostras das fezes de cada animal foram coletadas diretamente no piso das baias, imediatamente após a defecação. A coleta foi realizada durante três dias consecutivos, descartando-se a porção que entrasse em contato com solo. As amostras de fezes, devidamente identificadas, foram acondicionadas em sacos plásticos e congeladas a $-10{ }^{\circ} \mathrm{C}$. Posteriormente, foram descongeladas e pré-secas em estufa de ventilação forçada a $55^{\circ} \mathrm{C}$ por 72 horas e moídas em moinho com peneira com crivos de $1 \mathrm{~mm}$. A partir das três amostras moídas de fezes, obteve-se uma amostra composta por animal, as quais foram armazenadas para posteriores análises laboratoriais. Durante ensaio de digestibilidade, foram coletadas amostras dos alimentos fornecidos.
A excreção de matéria seca fecal foi estimada a partir da técnica do indicador interno(Cochran et al., 1986) utilizando-se a fibra indigestível em detergente neutro (FDNi) como indicador. Os teores de FDNi das amostras de fezes, bem como de alimentos (volumosos e ingredientes do concentrado) e das sobras, foram obtidos após incubação in situ por 240 horas, conforme recomendado por Casali et al. (2008).

O cálculo de produção fecal (PF) foi realizado pela fórmula: PF (kg/MS/dia) = (consumo de FDNi/\%FDNi nas fezes)*100. O cálculo da digestibilidade aparente (DA) dos nutrientes foi realizado pela fórmula: DA (\%) = [(nutriente ingerido - nutriente excretado)/nutriente ingerido] $\times 100$.

Os dados foram submetidos à análise de regressão por meio do SAS (Statistical Analysis System, versão 8.2), adotando-se o nível de significância de 5\%.

\section{Resultados e Discussão}

O consumo de matéria seca decresceu linearmente à medida que a torta de dendê foi incluída na dieta (Tabela 3). Para cada $1 \%$ de inclusão de torta de dendê na dieta das novilhas, os consumos de MS, expressos em kg/dia, g/kg $\mathrm{PC}^{0,75}$ e \%PC, reduziram em $0,10 \mathrm{~kg}, 1,41$ g e 0,03 ponto percentual, respectivamente. Pela equação de regressão, observou-se que o consumo de matéria seca no nível mais elevado de inclusão da torta de dendê foi de 54,5; 47,0 e 39,3\% menor se comparado à dieta controle, quando

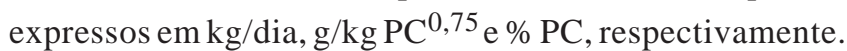

Avaliando níveis de substituição da silagem de capim elefante pela torta de dendê na dieta de ovinos, Bringel et al. (2011) obtiveram resposta quadrática para o consumo de matéria seca. Segundo o autor, o aumento no teor de extrato

Tabela 3 - Consumos, equações de regressão, coeficiente de determinação $\left(\mathrm{R}^{2}\right)$ de dietas contendo torta de dendê

\begin{tabular}{|c|c|c|c|c|c|c|}
\hline \multirow[t]{2}{*}{ Item } & \multicolumn{4}{|c|}{ Nível de inclusão da torta de dendê (\%) } & \multirow[t]{2}{*}{ Equação de regressão } & \multirow[t]{2}{*}{$\mathrm{R}^{2}$} \\
\hline & 0 & 12 & 23 & 34 & & \\
\hline & \multicolumn{4}{|c|}{$\mathrm{kg} / \mathrm{dia}$} & & \\
\hline Proteína bruta & 0,97 & 0,89 & 0,58 & 0,45 & $\hat{Y}=1,00-0,02 x^{* *}$ & 0,67 \\
\hline Fibra em detergente neutro & 2,13 & 2,18 & 1,62 & 1,35 & $\hat{Y}=2,26-0,02 x^{* *}$ & 0,41 \\
\hline Carboidratos não-fibrosos & 2,79 & 2,38 & 1,39 & 1,08 & $\hat{Y}=2,84-0,05 x^{* *}$ & 0,77 \\
\hline $\mathrm{NDT}_{\mathrm{OBS}}$ & \multicolumn{4}{|c|}{$\mathrm{g} / \mathrm{kg} \mathrm{PC}^{0,75}$} & & \\
\hline Matéria seca & 100,48 & 91,02 & 67,34 & 54,64 & $\hat{Y}=102,76-1,41 x^{* *}$ & 0,78 \\
\hline \multirow[t]{2}{*}{$\mathrm{NDT}_{\text {OBS }}$} & 77,82 & 71,13 & 53,79 & 42,02 & $\hat{Y}=80,07-1,09 x^{* *}$ & 0,78 \\
\hline & \multicolumn{4}{|c|}{$\%$ PC } & & \\
\hline Matéria seca & 2,56 & 2,31 & 1,81 & 1,44 & $\hat{Y}=2,62-0,03 x^{* *}$ & 0,80 \\
\hline
\end{tabular}

** $=\mathrm{P}<0,01 ; *=\mathrm{P}<0,05 ;{ }^{\text {ns }}=\mathrm{P}>0,05$. 
etéreo e o tipo de óleo presente na torta de dendê provocaram a redução no consumo de matéria seca.

Teores superiores a $50 \mathrm{~g} / \mathrm{kg}$ de extrato etéreo na dieta podem comprometer o consumo de matéria seca, seja por mecanismos regulatórios que controlam a ingestão de alimentos, seja pela capacidade limitada dos ruminantes de oxidar os ácidos graxos (Palmquist \& Mattos, 2006). O teor de extrato etéreo foi superior a $50 \mathrm{~g} / \mathrm{kg}$ a partir da dieta contendo 23\% de torta de dendê(Tabela 2), entretanto, o consumo de MS apresentou comportamento linear decrescente a partir do nível de $11,9 \%$ de inclusão, comprovando que outros fatores estão ligados à redução da ingestão.

Além do teor de extrato etéreo, um dos fatores que podem ter causado redução no consumo das dietas com a inclusão da torta de dendê é o tipo de óleo presente nesse subproduto. Segundo Hartley (1977), citado por Furlan Júnior et al. (2006), a torta de dendê apresenta como composição dos lipídeos 47,5\% de ácido láurico e 16,4\% de ácido mirístico. De acordo com Palmquist \& Mattos (2006), esses ácidos apresentam natureza anfifílica, uma vez que são solúveis tanto em solventes orgânicos como em água sendo, portanto mais tóxicos e com maior potencial de inibição de consumo.

O decréscimo observado no consumo de matéria seca também pode estar associado ao maior teor de lignina da torta de dendê - mais provável neste caso (Tabela 1). O mecanismo de ação da lignina parece envolver efeito físico, por formação de uma barreira sobre a hemicelulose e celulose e por impedir a adesão dos microrganismos à parede celular, prejudicando sua digestão (Thiago \& Gill, 1993) e o consumo.

Pela equação de regressão, verifica-se que níveis maiores que 6,9\% de inclusão da torta de dendê na ração resultam em consumo inferior a 5,6 kg de matéria seca/dia, valor recomendado pelo NRC (2001) para atender à exigência diária de novilhas com peso corporal de 200 kg e ganho de $0,750 \mathrm{~kg} / \mathrm{dia}$.

Segundo Silva et al. (2005), a concentração e a qualidade da proteína na dieta podem influenciar o consumo de alimentos pelos ruminantes, alterando tanto o mecanismo físico como o fisiológico no controle da ingestão. Observando a composição bromatológica da torta de dendê (Tabela 1), verifica-se que grande parte da proteína está ligada à parede celular na forma de nitrogênio insolúvel em detergente neutro (NIDN) ou nitrogênio insolúvel em detergente ácido (NIDA). Dessa forma, os altos teores de NIDN e NIDA da torta de dendê (Tabela 1) em relação aos outros ingredientes da dieta podem ter causado efeito negativo no consumo de MS e menor desempenho dos animais. Bringel et al. (2011) avaliaram a substituição da silagem de capim-elefante pela torta de dendê em dietas para ovinos e observaram aumento nos teores de PB das dietas, porém, grande parte dessa proteína estava complexada à parede celular, o que poderia ter afetado sua disponibilidade aos microrganismos do rúmen.

As ingestões de $\mathrm{PB}$ reduziram linearmente à medida que a torta de dendê foi incluída na dieta (Tabela 3). Esse fato deve-se à redução no consumo de MS das dietas com inclusão da torta de dendê. De acordo com equações de regressão, a inclusão de $1 \%$ de torta de dendê na dieta diminuiu em $20 \mathrm{~g} /$ dia o consumo de PB (kg MS/dia), o que representa redução no consumo desse nutriente em relação à dieta padrão de $68 \%$ quando a torta de dendê foi incluída na dieta no nível de 34\%.

Os consumos de FDN, expressos em kg/dia e \%PC, sofreram redução com a inclusão da torta de dendê na dieta. De acordo com as equações de regressão, a inclusão de 1\% de torta de dendê na dieta causou diminuição em 0,02 kg/dia e 0,007 ponto percentual no consumo de FDN. De acordo com Mertens (1987), o consumo ótimo de FDN para animais em crescimento é de $1 \%$ do peso corporal. Por outro lado, o consumo de FDN acima de 1,2\% do peso corporal é um dos principais mecanismos físicos reguladores do consumo de matéria seca. Dessa forma, a resposta negativa para o consumo de matéria seca com aumento do nível de torta de dendê na dieta pode não ter relação com o consumo desta fração fibrosa, uma vez que os valores variaram de 0,9 a 0,65\% do peso corporal das novilhas (Tabela 3), abaixo do limite sugerido por Mertens (1987).

Não houve efeito dos níveis de torta de dendê sobre a ingestão de EE quando expressa em kg/dia $(\mathrm{P}>0,05)$. Esse comportamento é atribuído à diminuição do consumo de MS com a inclusão da torta de dendê às dietas. Dessa forma, mesmo com a elevação do teor de EE das dietas com inclusão da torta de dendê, o consumo de EE pelas novilhas manteve-se próximo de $0,22 \mathrm{~kg} /$ dia, provavelmente em virtude do mecanismo de controle fisiológico utilizado pelos animais para manter o nível de consumo de EE de acordo com sua capacidade de utilização. $\mathrm{O}$ teor de EE na dieta pode inibir a ingestão de MS por ação dos hormônios intestinais, por sua própria oxidação no fígado, pela redução da digestão da fibra e pela baixa aceitação pelos bovinos (NRC, 2001). Bringel et al. (2011) observaram maior consumo de EE no nível de 50\% de inclusão de torta de dendê em substituição à silagem de capim-elefante para ovinos. Já Carvalho et al. (2007a) observaram maior consumo de EE, obtido a partir das equações de regressão quadrática no nível de inclusão de $25,9 \%$ de torta de dendê em substituição ao feno de capim-tifton 85 em dietas para ovinos. Esses autores 
destacaram que os teores de EE não limitaram a ingestão, já que o consumo de MS foi reduzido antes do consumo máximo de extrato etéreo.

Foi observada redução linear no consumo de NDT $(\mathrm{P}<0,01)$, com queda de $0,07 \mathrm{~kg} /$ dia e $1,09 \mathrm{~g} / \mathrm{kg} \mathrm{PC}^{0,75}$ para cada $1 \%$ de torta de dendê adicionada à dieta. Segundo Mertens (1992), o consumo de matéria seca está diretamente relacionado ao atendimento das exigências energéticas dos animais. Desse modo, a redução no consumo de MS, associada ao menor conteúdo de CNF e NIDN, NIDA e lignina da torta de dendê, foi o principal responsável pela redução no consumo de NDT pelas novilhas. Redução de 34,8 g no consumo de NDT para cada 1\% de casca de café adicionada à dieta de novilhas leiteiras foi observada por Souza et al. (2006), que atribuíram esse comportamento à redução no consumo de EE e CNF, nutrientes de alta digestibilidade e elevado valor energético.

Houve efeito linear negativo dos níveis de torta de dendê sobre a digestibilidade da MS ( $<<0,01)$, estimandose redução de 0,003 unidade para cada $1 \%$ de torta de dendê adicionada à dieta total (Tabela 4).

A inclusão da torta de dendê reduziu os níveis de CNF das dietas tidos como de rápida e completa disponibilidade no trato gastrointestinal dos ruminantes (Allen \& Mertens, 1987) e aumentou os teores de FDN, FDA e EE das dietas, presentes em elevada concentração na torta de dendê (Tabela 1), que podem ser considerados a provável causa da redução na digestibilidade da MS.

Avaliando a degradabilidade da MS da torta de dendê, Carvalho et al. (2006) concluíram que seu menor aproveitamento no rúmen pode ter sido em função do conteúdo fibroso altamente lignificado, no qual está presente em boa parte dos compostos nitrogenados. Assim, o aumento da lignina nas dietas com inclusão da torta de dendê também contribuiu com a redução da digestibilidade da MS. Os valores de digestibilidade aparente da MS das dietas com torta de dendê estão de acordo com os citados por Silva et al. (2005), que obtiveram valores de digestibilidade da MS de 67,86 e 66,46\%, respectivamente, para os níveis de substituição de 15 e 30\% do concentrado à base de milho e farelo de soja pela torta de dendê na alimentação de cabras lactantes.

A digestibilidade da PB apresentou resposta quadrática $(\mathrm{P}<0,01)$ com a inclusão de torta de dendênas dietas (Tabela 4). A redução na digestibilidade da PB está associada aos maiores teores de NIDN e, principalmente, NIDA presentes na torta de dendê em relação aos outros ingredientes da dieta (Tabela 1). Os teores de NIDA dos alimentos interferem na digestibilidade da proteína bruta por serem mais resistentes e praticamente indigestíveis e por estarem comumente associados à lignina e a outros compostos de difícil degradação (Van Soest, 1994; Licitra et al., 1996). A inclusão da torta de dendê elevou os teores de NIDA nas dietas (Tabela 2), influenciando negativamente o aproveitamento da $\mathrm{PB}$, como consequência do aumento nos teores de proteína insolúvel em detergente ácido (PIDA).

Em pesquisa com ovinos, Bringel et al. (2011) sugeriram que o aproveitamento da PB diminui com o aumento nos teores e do consumo da NIDA quando a silagem de capimelefante é substituída pela torta de dendê em $64 \%$.

O aproveitamento da proteína bruta correlaciona-se negativamente com o teor de nitrogênio ligado à fração fibrosa do alimento, o que, possivelmente, contribuiu de forma negativa na degradação ruminal da proteína bruta e outros nutrientes das dietas contendo torta de dendê. Segundo Bringel et al. (2011), a substituição da silagem de capim-elefante pela torta de dendê eleva os teores de proteína bruta das dietas; porém, grande parte dessa proteína se encontra complexada à parede celular, o que pode prejudicar sua disponibilidade aos microrganismos do rúmen.

Resultados semelhantes foram observados por Teles et al. (2010), que observaram redução na digestibilidade da proteína bruta com a adição de subproduto de manga (Mangifera indica) na ensilagem do capim-elefante. Para cada $1 \%$ de inclusão de subproduto de manga, os autores observaram redução de 1,23 ponto percentual na digestibilidade da proteína bruta em dietas para ovinos.

Rocha Neto (2008) também atribuiu a redução da digestibilidade da PB em dietas com farelo de cacau para novilhas leiteiras aos teores de nitrogênio insolúvel em

Tabela 4 - Coeficientes de digestibilidade, equações de regressão, coeficientes de determinação $\left(\mathrm{R}^{2}\right)$ de dietas contendo torta de dendê

\begin{tabular}{|c|c|c|c|c|c|c|}
\hline \multirow[t]{2}{*}{ Item } & \multicolumn{4}{|c|}{ Nível de inclusão da torta de dendê (\%) } & \multirow[t]{2}{*}{ Equação de regressão } & \multirow[t]{2}{*}{$\mathrm{R}^{2}$} \\
\hline & 0 & 12 & 23 & 34 & & \\
\hline Matéria seca & 0,7561 & 0,7194 & 0,6827 & 0,6550 & $\hat{Y}=0,7449-0,003 X^{* *}$ & 0,85 \\
\hline Proteína bruta & 0,8185 & 0,7579 & 0,7206 & 0,7238 & $\hat{Y}=0,8195-0,0069 x+0,0001 x^{2 * *}$ & 0,75 \\
\hline Fibra em detergente neutro & 0,5631 & 0,5513 & 0,5502 & 0,5088 & $\hat{Y}=0,5682-0,0014 x^{*}$ & 0,32 \\
\hline Carboidratos não-fibrosos & 0,8974 & 0,8821 & 0,9082 & 0,8097 & $\hat{Y}=0,8896+0,0033 x-0,0001 x^{2 * *}$ & 0,52 \\
\hline Extrato etéreo & 0,6887 & 0,7820 & 0,8582 & 0,9097 & $\hat{Y}=0,6974+0,0065 x * *$ & 0,81 \\
\hline Nutriente digestíveis totais & 0,7756 & 0,7811 & 0,7986 & 0,7686 & $\hat{Y}=0,7815^{n s}$ & - \\
\hline
\end{tabular}

** = $\mathrm{P}<0,01 ; *=\mathrm{P}<0,05 ;{ }^{\mathrm{ns}}=\mathrm{P}>0,05$. 
detergente neutro e nitrogênio insolúvel em detergente ácido do subproduto em relação aos outros ingredientes da dieta. Da mesma forma, a redução na digestibilidade da PB de dietas com casca de café para novilhas observada por Souza et al. (2006) está associada aos maiores teores de nitrogênio insolúvel deste subproduto.

Houve redução linear da digestibilidade aparente da FDN $(\mathrm{P}<0,05)$ com a inclusão da torta de dendê sobre a digestibilidade aparente da FDN (Tabela 4). Os coeficientes reduziram 0,0014 unidade para cada 1\% de torta de dendê adicionada na dieta, respectivamente. O decréscimo observado na digestibilidade da FDN pode ser reflexo do maior teor de lignina contido na torta de dendê (Tabela 2), o que, segundo Van Soest (1994), influencia a baixa disponibilidade de nutrientes para os microrganismos ruminais.

Efeitos negativos da lignina sobre a digestibilidade da FDN também foram observados por Teixeira et al. (2007), que verificaram redução de 0,29 ponto percentual para cada $1 \%$ de casca de café adicionada à dieta de novilhas leiteiras. Rocha Neto (2008) também observou baixa digestibilidade da FDN (38,6\%) em dietas com farelo de cacau para novilhas, devido à influência dos altos teores de lignina das dietas.

A redução na digestibilidade da fração fibrosa dos alimentos também tem sido observada em algumas situações quando há elevado teor de EE na dieta (Jenkins, 1993). O elevado teor de EE das dietas com a inclusão da torta de dendê também pode ter influenciado negativamente a digestibilidade da FDN. Ao avaliarem a digestibilidade de dietas contendo 15 ou 30\% de torta de dendê, Silva et al. (2005) relataram ter observado efeito depressivo dos teores de EE das dietas, os quais foram superiores a 5\% na MS da dieta, causando baixa digestibilidade da FDN.

A digestibilidade aparente do EE aumentou com os níveis de torta de dendê na dieta, apresentando aumento de 0,0065 unidade para cada $1 \%$ de torta de dendê adicionada. O aumento da digestibilidade do EE pode ser reflexo da elevação do percentual de EE nas dietas com a inclusão de torta de dendê, associado ao menor consumo de MS dessas dietas e ao provável aumento no tempo de retenção da digesta, beneficiando a digestão desse nutriente. No estudo realizado por Carvalho et al. (2007b), a digestibilidade aparente do EE aumentou linearmente com a inclusão da torta de dendê. Segundo o autor, esse efeito é explicado pelo aumento do consumo e da proporção de EE na MS ingerida pelos ovinos com a substituição do feno de capimtifton 85 pela torta de dendê.

Não houve efeito dos níveis de torta de dendê sobre o teor dos nutrientes digestíveis totais (NDT), cujo valor médio foi de $0,7815 \%$. Os valores observados para NDT das dietas foram superiores aos nutrientes digestíveis totais estimados ( $\mathrm{NDT}_{\mathrm{EST}}$ ), provavelmente devido ao aumento na digestibilidade do extrato etéreo das dietas. Os teores de NDT das dietas estão de acordo com os citados por Bringel et al. (2011), que observaram aumento para mais de $70 \%$ de NDT nas dietas para ovinos com maior concentração de torta de dendê.

O ganho de peso diário das novilhas reduziu linearmente com a inclusão de torta de dendê na dieta (Tabela 5). Pela equação de regressão, estima-se redução diária de 15 g no ganho de peso corporal das novilhas para cada $1 \%$ de torta de dendê adicionada à dieta.

Os elevados teores de NIDN e NIDA das dietas (Tabela 2) estão diretamente ligados à redução do desempenho das novilhas. O menor aproveitamento da proteína alterou o consumo e a digestibilidade da matéria seca e dos nutrientes, o que refletiu em menor consumo energético, ocasionando menor crescimento das novilhas.

Em trabalho com novilhas Holandês $\times$ Zebu recebendo casca de café em substituição ao milho, Souza et al. (2006) observaram redução no desempenho das novilhas que receberam dietas contendo casca de café na ração em função da redução na digestibilidade da MS e dos nutrientes, associada à menor ingestão de NDT. Resultados semelhantes foram obtidos por Teixeira et al. (2007), em pesquisa com o mesmo subproduto na alimentação de novilhas em substituição à silagem de milho.

O ganho de peso diário (GPD) estimado para este estudo foi de $0,750 \mathrm{~kg} / \mathrm{dia}$ (NRC, 2001), no entanto, os ganhos médios diários obtidos com as dietas com 0; 12 e 23\% de inclusão da torta de dendê foram superiores ao valor

Tabela 5 - Desempenho, equações de regressão e coeficiente de determinação $\left(\mathrm{R}^{2}\right)$ de novilhas alimentadas com dietas contendo torta de dendê

\begin{tabular}{lcccccc}
\hline Item & \multicolumn{3}{c}{ Nível de torta de dendê (\%) } & & Equação de regressão \\
\cline { 2 - 4 } & 0 & 12 & 23 & 34 & \\
\hline Peso inicial, kg & 197,5 & 212,0 & 175,3 & 191,3 & \\
Peso final, kg & 271,5 & 281,1 & 237,3 & 228,5 & & \\
Ganho de peso total, kg & 74,5 & 69,1 & 62,0 & 37,5 & & $\hat{Y}=74,57-0,95 x^{* *}$ \\
Ganho de peso, kg/animal/dia & 1,06 & 0,99 & 0,89 & 0,54 & & $\hat{Y}=1,12-0,015 x^{* *}$ \\
Conversão alimentar & 5,57 & 6,21 & 4,01 & 5,48 & & $\hat{Y}=5,68^{\text {ns }}$ \\
\hline
\end{tabular}

** $=\mathrm{P}<0,01,{ }^{\mathrm{ns}}=$ não-significativo. 
pretendido. De acordo com as equações de regressão, o ganho predito pelo NRC (2001) seria obtido com a inclusão de $24,9 \%$ de torta de dendê na dieta.

Na fase de recria das novilhas, o principal objetivo deve ser a obtenção de ganho de peso suficiente para que se consiga alcançar o peso de cobertura mais cedo possível, que é de $330 \mathrm{~kg}$ pra novilhas mestiças (NRC, 2001). Entretanto, para novilhas de porte médio, deve-se evitar ganhos superiores a $0,9 \mathrm{~kg} / \mathrm{dia}$ durante a puberdade para evitar má-formação do úbere e menor produção de leite na primeira lactação (Campos, 2005).

É importante destacar que a inclusão da torta de dendê, mesmo reduzindo o consumo de nutrientes e o desempenho dos animais, quando incluída em até $24,9 \%$ da dieta total, proporciona ganhos diários de $750 \mathrm{~g}$, desempenho compatível com programas de criação para que os animais atinjam o parto aos 24 meses de idade.

A conversão alimentar não foi alterada pela inclusão da torta de dendê na dieta $(\mathrm{P}>0,05)$, sendo observada média de 5,68 kg de MS por kg de ganho de peso (Tabela 5). Marques et al. (2000) avaliaram o desempenho de novilhas em confinamento alimentadas com dietas contendo casca, farinha de varredura e raspa da mandioca em substituição ao milho e observaram conversão alimentar de 6,6 kg de MS por kg de PV.

\section{Conclusões}

A inclusão de torta de dendê na dieta reduz o consumo de nutrientes e o desempenho de novilhas leiteiras em crescimento, porém, quando utilizada em até $24,6 \%$ da dieta total, dietas com torta de dendê proporciona ganho de peso compatível com o obtido em programas de recria visando à parição aos 24 meses de idade.

\section{Referências}

ALLEN, M.S.; MERTENS, D.R. Evaluating constraints on fiber digestion by rumen microbes. Journal of Nutrition, v.118, n.1, p.261-270, 1988.

BRINGEL, L.M.L.; NEIVA, J.N.M.; ARAÚJO, V.L. et al. Consumo, digestibilidade e balanço de nitrogênio em borregos alimentados com torta de dendê em substituição à silagem de capim-elefante. Revista Brasileira de Zootecnia, v.40, n.9, p.1975-1983, 2011.

CAMPOS, J.M.S.; ASSIS, A.J. Alimentação de novilhas leiteiras. In: SIMPÓSIO MINEIRO DE NUTRIÇÃO DE GADO DE LEITE, 3., 2005, Belo Horizonte. Anais... Belo Horizonte: UFMG: Escola de Medicina Veterinária, 2005. p.155-176.

CARVALHO, G.G.P.; PIRES, A.J.V.; VELOSO, C.M. et al. Degradabilidade ruminal de concentrados e subprodutos agroindustriais. Archivos de Zootecnia, v.55, n.212, p.397-400, 2006.

CARVAlHO, E.M.; PEREIRA, M.L.A.; ALMEIDA, P.J.P. et al. Torta de dendê (Elaeis guineensis, Jacq) em substituição ao feno de Tifton 85 (Cynodon spp) na alimentação de ovinos Consumo. In: CONGRESSO NACIONAL DE ZOOTECNIA, 17., 2007, Londrina. Anais... Zootec: Londrina, [2007a]. (CD-ROM).

CARVALHO, E.M.; PEREIRA, M.L.A.; ALMEIDA, P.J.P. et al. Torta de dendê (Elaeis guineensis, Jacq) em substituição ao feno de Tifton 85 (Cynodon spp) na alimentação de ovinos Digestibilidade. In: CONGRESSO NACIONAL DE ZOOTECNIA, 17., 2007, Londrina. Anais... Londrina: Zootec, [2007b]. (CD-ROM).

CASALI, A.O.; DETMANN, E.; VALADARES FILHO, S.C. et al. Influência do tempo de incubação e do tamanho de partículas sobre os teores de compostos indigestíveis em alimentos e fezes bovinas obtidos por procedimentos in situ. Revista Brasileira de Zootecnia, v.37, n.2, p.335-342, 2008.

CASTRO, K.J.; NEIVA, J.N.M.; OLIVEIRA, R.C. et al. Viabilidade econômica do uso de subprodutos agroindustriais na dieta de novilhas leiteiras. In: CONGRESSO NORDESTINO DE PRODUÇÃO ANIMAL, 5., 2008, Aracaju. Anais... Aracajú: SNPA, [2008]. (CD-ROM).

COCHRAN, R.C.; ADANS, D.C.; WALLACE, J.D. et al. Predicting digestibility of different diets with internal markers: evaluation of four potential markers. Journal of Animal Science, v.63, n.5, p.1476-1483, 1986.

FERREIRA, A.C.H.; RODRIGUEZ, N.M.; NEIVA, J.N.M. et al. Desempenho produtivo de ovinos alimentados com silagens de capim-elefante contendo do processamento de frutas. Revista Ciência Agronômica, n.2, v.40, p.315-322, 2009.

FURLAN JÚNIOR, J.; KALTNER, F.J.; AZEVEDO, G.F.P. et al. Biodiesel: porque tem que ser dendê. Belém: Embrapa Amazônia Oriental; Palmasa, 2006. 205p.

GARCIA, J.A.S.; VIEIRA, P.F.; CECON, P.R. et al. Desempenho de bovinos leiteiros em fase de crescimento alimentados com farelo de girassol. Ciência Animal Brasileira, v.7, n.3, p.223-233, 2006.

GRASSER, L.A.; FADEL, J.G.; GARNETT, I. et al. Quantity and economic importance of nine selected by-products used in California dairy rations. Journal of Dairy Science, v.78, n.4, p.962-971, 1995.

HALL, M.B. Calculation of non-structural carbohydrate content of feeds that contain non-protein nitrogen. Gainesville: University of Florida, 2000. p.A-25 (Bulletin, 339).

JENKINS, T.C. Symposium: advances in ruminant lipid metabolism - Lipid metabolism in the rúmen. Journal of Dairy Science, v.76, n.12, p.3851-3863, 1993.

LICITRA, G.; HERNANDEZ, T.M.; VAN SOEST, P.J. Standardizationn of procedures for nitrogen fractionation of ruminant feeds. Animal Feed Science Technology, v.57, n.4, p.347-358, 1996.

MARQUES, J.A.; PRADO, I.N.; ZEOULA, L.M. et al. Avaliação da mandioca e seus resíduos industriais em substituição ao milho no desempenho de novilhas confinadas. Revista Brasileira de Zootecnia, v.29, n.5, p.1528-1536, 2000.

MENDES NETO, J.; CAMPOS, J.M.S.; VALADARES FILHO, S.C. et al. Consumo, digestibilidade, desempenho, desenvolvimento ponderal e economicidade de dietas com polpa cítrica em substituição ao feno de capim-tifton 85 para novilhas leiteiras. Revista Brasileira de Zootecnia, v.36, n.3, p.626-634, 2007.

MERTENS, D.R. Analysis of fiber in feeds and its uses in feed evaluation and ration formulation. In: SIMPÓSIO INTERNACIONAL DE RUMINANTES, REUNIÃO ANUAL DA SOCIEDADE BRASILEIRA DE ZOOTECNIA, 29., 1992, Lavras. Anais... Lavras: Sociedade Brasileira de Zootecnia, 1992. p.1-32.

MERTENS, D.R. Predicting intake and digestibility using mathematical models of ruminal function. Journal of Animal Science, v.64, n.7, p.1548-1558, 1987.

NATIONAL RESEARCH COUNCIL - NRC. Nutrient requirement of dairy cattle. 7.ed. Washington, D.C.: National Academy Press, 2001. 381p. 
PALMQUIST, D.L.; MATTOS, W.R.S. Metabolismo de lipídeos. In: BERCHIELLI, T.T.; PIRES, A.V.; OLIVEIRA, S.G. (Eds.) Nutrição de ruminantes. Jaboticabal: Funep, 2006. p.287-310.

ROCHA NETO A.L. Farelo de cacau na dieta de novilhas leiteiras. 2008. 65f. Dissertação (Mestrado em Zootecnia Produção de Ruminantes). Universidade Estadual do Sudoeste da Bahia, Itapetinga.

SARTORI, R. Manejo reprodutivo da fêmea leiteira. Revista Brasileira de Reprodução Animal, v.31, n.2, p.153-159, 2007.

SILVA, D.J.; QUEIROZ, A.C. Análise de alimentos (métodos químicos e biológicos) 2.ed. Viçosa, MG: Universidade Federal de Viçosa, 2002. 165p.

SILVA, H.G.O.; PIRES, A.J.V; SILVA, F.F. et al. Digestibilidade aparente de dietas contendo farelo de cacau ou torta de dendê em cabras lactantes. Pesquisa Agropecuária Brassileira, v.40, n.4, p.405-411, 2005.

SOUZA, A.L.; GARCIA, R.; BERNARDINO, F.S. et al. Casca de café em dietas para novilhas leiteiras: consumo, digestibilidade e desempenho. Revista Brasileira de Zootecnia, v.35, n.3, p.921-927, 2006.

SNIFFEN, C.J.; O’CONNOR, J.D.; FOX, D.G. A net carbohydrate and protein system for evaluating cattle diets; II - Carbohydrte and protein availability. Jornal Animal Science, v.70, n.3562-3577, 1992.
TEIXEIRA, R.M.A.; CAMPOS, J.M.S.; VALADARES FILHO, S.C. et al. Consumo, digestibilidade e desempenho de novilhas alimentadas com casca de café em substituição à silagem de milho. Revista Brasileira de Zootecnia, v.36, n.4, p.968-977, 2007.

TELES, M.M.; NEIVA, J.N.M., HERCULANO, R.C. et al. Consumo, digestibilidade de nutrientes e balanço de nitrogênio da silagem de capim-elefante com adição de pedúnculo de caju desidratado. Ciência Rural, v.40, n.2, p.427-433, 2010.

RÊGO, M.M.T.; NEIVA, J.N.M.; REGO, A.C. et al. Intake, nutrients digestibility and nitrogen balance of elephant grass silages with mango by-product addition. Revista Brasileira de Zootecnia, v.39, n.1, p.74-80, 2010.

TOMLINSON, D.J.; JAMES, R.E.; MCGILLIARD, E.D. Effect of varying levels of neutral detergent fiber and total digestible nutrients on intake and growth of Holstein heifers. Journal of Dairy Science, v.74, n.2, p.537-545, 1991.

THIAGO, L.R.L.; GILL, M. Consumo voluntário: fatores relacionados com a degradação e passagem da forragem pelo rúmen. Campo Grande: EMBRAPA Gado de corte, 1993. 65p. (Documentos, 43).

VAN SOEST, P.J. Nutritional ecology of the ruminant. 2.ed. Ithaca: Cornell University Press, 1994. 476p.

VAN SOEST, P.J.; MASON, V.C. The influence of Maillard reaction upon the nutritive value of fibrous feeds. Animal Feed Science and Technology, v.32, n.1, p.45-53, 1991. 